\title{
Characterization of a Rat Gene, rMAL, Encoding a Protein with Four Hydrophobic Domains in Central and Peripheral Myelin
}

\author{
N. Schaeren-Wiemers, ${ }^{1, a}$ D. M. Valenzuela, ${ }^{2}$ M. Frank, ${ }^{1}$ and M. E. Schwab ${ }^{1}$ \\ ${ }^{1}$ Institute for Brain Research, University of Zurich, Switzerland and ${ }^{2}$ Regeneron Pharmaceuticals, Inc., Tarrytown, \\ New York 10591
}

\begin{abstract}
Wrapping and compaction of myelin sheaths around axons require specific membrane and membrane-associated proteins. Transmembrane proteins like proteolipid protein (PLP), the peripheral myelin protein 22 (PMP-22) and $P_{0}$ as well as myelin basic protein (MBP) are crucial for this process. We have isolated a rat cDNA, initially denominated NS 3, that is mainly expressed in the myelinating cells of the nervous system, the ollgodendrocytes and Schwann cells. The cDNA encodes a highly hydrophobic protein of $16.8 \mathrm{kDa}$ with four putative transmembrane domains. The putative NS 3 protein lacks a $\mathrm{N}$-terminal hydrophobic leader sequence and has no consensus sequence for $\mathrm{N}$-linked glycosylation. In contrast to PLP and PMP-22, the first and third putative transmembrane domain of the NS 3 protein contain charged amino acids, a feature which resembles the structure of gap junction proteins. Sequence analysis showed that NS 3 is the rat homolog of a human gene called MAL that was cloned from, and is expressed in various T-cell lines. Therefore, we call this gene rMAL (rat $M A L)$. In the nervous system, the expression of rMAL, mRNA begins after birth and is highest during myelination. In situ hybridization shows that rMAL mRNA is exclusively expressed in white and gray matter oligodendrocytes in the CNS and in myelinating Schwann cells in peripheral nerves. Immunohistochemistry using a peptide-specific antibody localized the rMAL protein in the myelinated areas of the CNS and PNS. Furthermore, we demonstrate by immunoblot analysis that rMAL is a component of myelin. Its structure and distribution suggest that the rMAL protein might play an important role in compact myelin. We propose that the name rMAL protein refers to rat Myelin And Lymphocyte protein.
\end{abstract}

[Key words: oligodendrocyte, Schwann cell, myelin-specific gene, myelin formation, in situ hybridization, four-hydrophobic domaln protein]

\footnotetext{
Received Nov. 9, 1994; revised Apr. 10, 1995; accepted Apr. 13, 1995.

We thank Dr. Ueli Suter for critical reading the manuscript. Special thanks to Franziska Christ for her skillful technical assistance and to Roland Schoeb for the photographic work. This study was supported by grants of the Swiss National Science Foundation (Grant No. 31-29981.90), the American Paralysis Association (Springfield, NJ), the Swiss Multiple Sclerosis Society, the Slack Gyr Foundation (Zurich), the International Research Institute for Paraplegia (Zurich), and Regeneron Pharmaceuticals, Inc. (Tarrytown, NY).

Correspondence should be addressed to N. Schaeren-Wiemers, Friedrich Miescher-Institute, P.O. Box 2543, CH-4002 Basle, Switzerland.

aPresent address: Friedrich Miescher-Institute, P.O. Box 2543, CH-4002 Basle, Swilzerland.

Copyright (C) 1995 Society for Neuroscience $0270-6474 / 95 / 155753-08 \$ 05.00 / 0$
}

During myelination the specialized plasma membrane of myelin forming cells wraps around the axons and is subsequently compacted. This task is performed in the CNS by oligodendrocytes and in the PNS by Schwann cells (for review, see Doyle and Colman, 1993). Specific membrane and membrane-associated proteins are required for (1) the initial contact between the proliferating oligodendrocytes or Schwann cells and the axons, (2) for the spiral wrapping of the processes around the axon, and (3) for the transport system for ions and essential molecules between the myelin lamellae (for review, see Hudson, 1990). The proteins that are thought to be involved in the process of wrapping and compaction are adhesion proteins such as myelin associated glycoprotein (MAG; for review, see Salzer et al., 1990), oligodendrocyte-myelin glycoprotein (OMgp; Mikol et al., 1990) and the myelin protein $\mathrm{P}_{0}$ (Filbin et al., 1990), hydrophobic proteins like proteolipid protein (PLP; for review see Nave and Milner, 1989) and peripheral myelin protein 22 (PMP22; for review, see Suter et al., 1993) and membrane-associated cytoplasmic proteins like myelin basic protein (MBP; for review, see Moscarello et al., 1989). The most abundant myelin protein in the CNS is PLP (for review, see Mikoshiba et al., 1991), a $28 \mathrm{kDa}$ protein that is not glycosylated and is thought to consist of four transmembrane domains (Milner et al., 1985; Popot et al., 1991, for review). In the PNS, PMP-22 (Welcher et al., 1991) is a $22 \mathrm{kDa}$ protein that also consists of four hydrophobic domains but is glycosylated (Snirpes et al., 1992). Both proteins lack a cleaved signal peptide. Mutations in the transmembrane domains of PLP will lead to hypomyelinations as it is known for the PLP gene in the rumpshaker and the jimpy mouse (Schneider et al., 1992), in the myelin deficient rat (Boison and Stoffel, 1989), and in the human Pelizaeus-Merzbacher disease (Hudson et al., 1989). The mutation in the trembler mouse, which is characterized by peripheral nerve demyelination, could be correlated to point mutations in the PMP-22 gene. Mutations in the same gene are the cause of the hereditary human peripheral neuropathy Charcot-Marie-Tooth type 1A (CMT1A; Suter et al., 1992). Recently, two additional genetic defects which cause a demyelinating type of CMT disease, type $1 \mathrm{~B}$ and $\mathrm{X}$, could be linked to a mutation in the gene for $\mathrm{P}_{0}$, the most abundant protein in the peripheral myelin (Hayasaka et al., 1993), and in the gene for the gap junction protein connexin 32 ( $\mathrm{Cx} 32$; Bergoffen et al., 1993). Cx32 belongs to the connexin superfamily class I (Bennett et al., 1991) or $\beta$ group (Gimlich et al., 1988) which is expressed in various cell types including oligodendrocytes and Schwann cells (Bergoffen et al., 1993; Dermietzel and Spray, 1993). Cx32 is a hydrophobic protein of $26-28 \mathrm{kD}$ that has no leader sequence and no glycosylation site and consists 
A

1 CGGAGCCGGAGGCGAGCTTGTCCAGTTCCAACGCCAGCTCGCAGGCATGGCCCCAGCAGC $M$ A P A A

61 AGCTTCGGGTGGCAGCACCCTGCCCAGTGGCTTCTCCGTCTTCGTCACCTTCCCTGACTT $\begin{array}{llllllllllllllllllllll}A & S & G & G & S & T & L & P & S & G & F & S & V & F & V & T & F & P & D & L\end{array}$

121 GCTCTTCATCTTTGAGTTTATCTTTGGAGGCCTGGTGTGGATCCTGATCGCCTCCTCCCT $\begin{array}{llllllllllllllllllll}I & F & I & F & E & F & I & F & G & G & L & V & \text { W } & I & L & I & A & S & S & L\end{array}$

CAGGATGCAGCCTACCACTGTGTGGCTGCCCTGTTTTACCTCAGTGCCTCAGTCCT $\begin{array}{llllllllllllllllllll}T & \text { L } & D & A & A & Y & H & C & \text { V } & \text { A } & \text { A } & \text { L } & \text { F } & \text { Y } & \text { L } & \text { S } & \text { A } & \text { S } & \text { V } & \text { L }\end{array}$

GGAAGCCCTGGCCACCATCACAATGTTCGATGGCTTTACCTACAGGCATTACCATGAGAA $\begin{array}{lllllllllllllllllllll}E & A & L & A & T & I & T & M & F & D & G & F & T & Y & R & H & Y & H & E & N\end{array}$

CATCGCTGCAGTGGTGTTCGCCTATGTGGCTACTCTGCTCTACGTGATCCATGCTGTGTT

\begin{tabular}{lllllllllllllllllllll}
$I$ & $A$ & $A$ & $V$ & $V$ & $F$ & $A$ & $Y$ & $V$ & $A$ & $T$ & $L$ & $L$ & $Y$ & $V$ & $I$ & $H$ & $A$ & $V$ & $F$ & 1 \\
\hline
\end{tabular}

Figure 1. Sequence and secondary structure analysis of the NS 3 cDNA. $A$, Nucleotide and deduced amino acid sequence of the rat NS 3 cDNA. Solid underlined regions correspond to putative membrane-spanning domains. $B$, Amino acid sequence (one letter code) comparison of human MAL (top sequence) and rat NS 3 (bottom sequence). Identical residues are indicated by solid vertical lines, and conservative amino acid substitutions are shown by colons. $C$, Hydrophobicity plot of rat MAL. The hydrophobicity index was calculated using the algorithm of Kyte and Doolittle (1982). D, Hypothetical model of rat MAL protein based on secondary structure analysis and the model for human MAL by Alonso and Weissman (1987). The position of charged amino acids (at neutral $\mathrm{pH}$ ) are indicated for positively (dark gray) and negatively (bright gray) charged amino acids. The putative transmembrane sequences I, III, and IV are predicted to be $\alpha$-helical, whereas transmembrane domain II forms a $\beta$-sheet. Note that in this mod$\mathrm{el}$, the $\mathrm{N}$ - and $\mathrm{C}$ - termini are on the cytoplasmic side of the membrane.
481

TTCCTTAATCAGATGGAAGTCTTCATAGGACAGCAGATTGGGAGCTGAAACCCAGATGCA $S \quad I \quad I \quad R \quad W \quad K \quad S \quad S$ *

541

601

661

721

781

841

901

961

1021

1081

1141

1201

1261

1321

1381

1441

1501

1561

1621

1681

1741

1801

1861

1921

1981

2041

2101

2161

ATTAACTGGTCAGCCTGTCTTCCCCATTAACTTCCTGGAACAGACTGAATGGTGGAGAAA AGAAAACAAGCCAAAAGAAAACAAAACAGACACAAAAACAAAAGGAAACCATGTTCGAGT CTCTTGGGTGTTACGTTTACCTTCTGTTAGGGTTTAGGGCTTGCTGAATTTAACTTCCAG CCAAAGGAGGAAAGAGTTGTCTTGGCGGGGGCCCTTTCTGCCCTTGACCAGGACAGTGGG TGGGAGCTTGGAACCTTGATCTGAAGAAATGACAATTTCCCCTTGACCCTTGGAGCAGGT CCTAACAATTGCCTTTCGGAATTTTCCACAAGCTCTTTGCACCACTCATCCCCTGGCATA TCTTAGATTTTGTGGATAGTCTAGGTGTCACAGGCACTGAAATTCACCCAACAGAGGTCT CTAGATAGATGTTCATGGTGGAAGATGAACCCCTTTGAAATACTTCATTAAATACCTTTA TGTCTCATGCTTCGGGTGGGGAACTGGGATGTTTTCATTCTCAGGAATCAGGGACTGACA CCTTTCTACTCAACTTTCTTCCTGCCAGAGTCCTTTGATGTAACCTGAACCTCAAGGGAC AATTCAGATGTGTGTGCTGGCCAGTCTTTCCCACAATGACTCACTGAGGATGCCACCCTC ACAACAGTGTCCACCAGGACAGTGTCTCCCTTGTAGGTGCATCCCAGGGAGCTCAAGGAA CAACAGTTTGCTAAATTAGAATCTTTTCAAGCTCAGAAAACTAGGTGTGGGCATTCCTTC TCTTCTTAGGGCTGATCTAAAATGCTCTAGTCTGTGTTTGGGCATGTTCTCAGATCATTT CTTTCGGGGAGAAGAGGGACCTGACTCCAGAGCAAAGGGAGAGACAATGGCTATTTCTGG CTGCCACATTCCAGGTGAGGGACATCTGACCTGAAAGAAGAAAGTATAATTAGGAAGGAC ATGGAGAGCCTGCAAAGTCAGACATCTGCTAGGAGATCTCACCTGGACCCCACAGTTTAA AGGATTGACAAACTAGAGTTGGAACCCCAGATGCAGGGACGTCCTGCCAGCCACCAGGAC TGCCAGGATTCTAGCCTCGGTCAGCTTCCACTAGCTGATGTTTTATTCTCCAACAAAGTG GGAGATTGAGACCTACAACCAAATTAGATTTGGGGAGTTTTCTACCTTGGTTCTGAGGAT GGAACCCAGGGGGTACACATGCTGGGTAAGCACTCTTCTCCTGGATCCCATCTTCAGCCC CAAATTGAGTCCCAGTGGCACATCCAGGAGGCCTTTGGTTATCCCAGCCATACTGGTACC CAAATCTGCCATTTGCCCCACTTAACACAGTCCCAATTTCATACTAAAACGCAACCACAA GATTAGGGGGATTTATTTTTTTAAATTAAAATATAAACTAAGAGATTATATGTAGTTCAT TATAATGGTTAACAAAGTCTGTTACTGAACGCTGACTGGGGTCGTCTTATATTTTCAACC AAACTGAACCATAACATTACACTAACCAGCAGCTCAACATGAGCGAGGGTTGGTTTTTTT GTTTTTGTTTTTTTTTTTGATAAGAAGAAAAGAGAGATGAAGGAAGGAAGAAAGGAACAA AGGAAGGGTGACTAAGATGAATTTTCC 2187 of four transmembrane domains. A single gap junction channel includes a dodecamer formed by six monomers of connexin in each membrane which are coupled together. The gap junction channel permits passage of small molecules up to about $1 \mathrm{kDa}$ in size. The third transmembrane domain has conserved polar, basic and acidic groups which may form an amphipathic helix in which the polar side (glutamine) forms the aqueous channel (for review, see Bennett et al., 1991).

By a differential screening approach described in detail in Schaeren-Wiemers et al. (1995), we have identified a gene, tentatively denominated NS 3, which is in the nervous system exclusively expressed in oligodendrocytes and Schwann cells. Here we describe the characterization of this gene, its relationship to the human gene MAL, its structural relationship to the four-hydrophobic domain proteins PI.P, PMP-22, and connexin 32, its developmental expression in the CNS and PNS and evidences by immunohistochemistry and immunoblots that the NS 3-now denominated rat MAL (rMAL)-protein is a component of myelin.

\section{Materlals and Methods}

cDNA cloning and sequence analysis. A cDNA library constructed in lambda ZAP II (Stratagene) from postnatal day 16 spinal cord was differentially screened for oligodendrocyte-specific genes (Schaeren-Wiemers et al., 1995). One of the isolated cDNA clones, denominated NS 3 , represented a full length sequence of $2187 \mathrm{bp}$. Sequence analysis was performed by using the ABI 373A DNA sequencer and Taq Dyedeoxy Terminator Cycle Sequencing Kit (Applied Biosystems, Inc., Foster City, $\mathrm{CA}$ ). The NS 3 sequence has been submitted to EMBL, accession number X82557.

Northern blot analysis. Total cellular RNA was isolated by the LiClprecipitation method described by Bothwell et al. (1990), electrophoresed through denaturing $1 \%$ formaldehyde gels, and transferred to ZETAProbe nylon membranes (Bio-Rad) in $10 \times$ SSC $(1 \times$ SSC: $0.15 \mathrm{M} \mathrm{NaCl}$, $0.05 \mathrm{M}$ Na-citrate; $\mathrm{pH} 7.0$ ). Hybridization was carried out in $0.5 \mathrm{M}$ sodium 


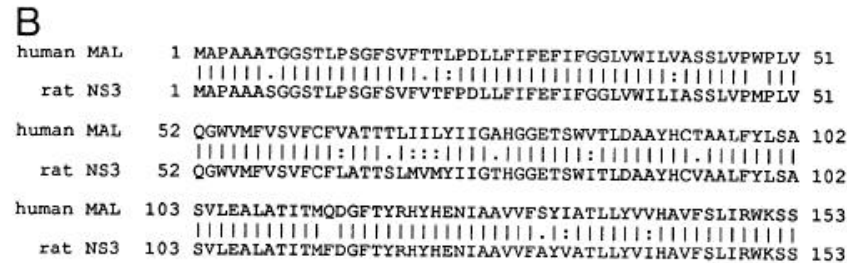

C
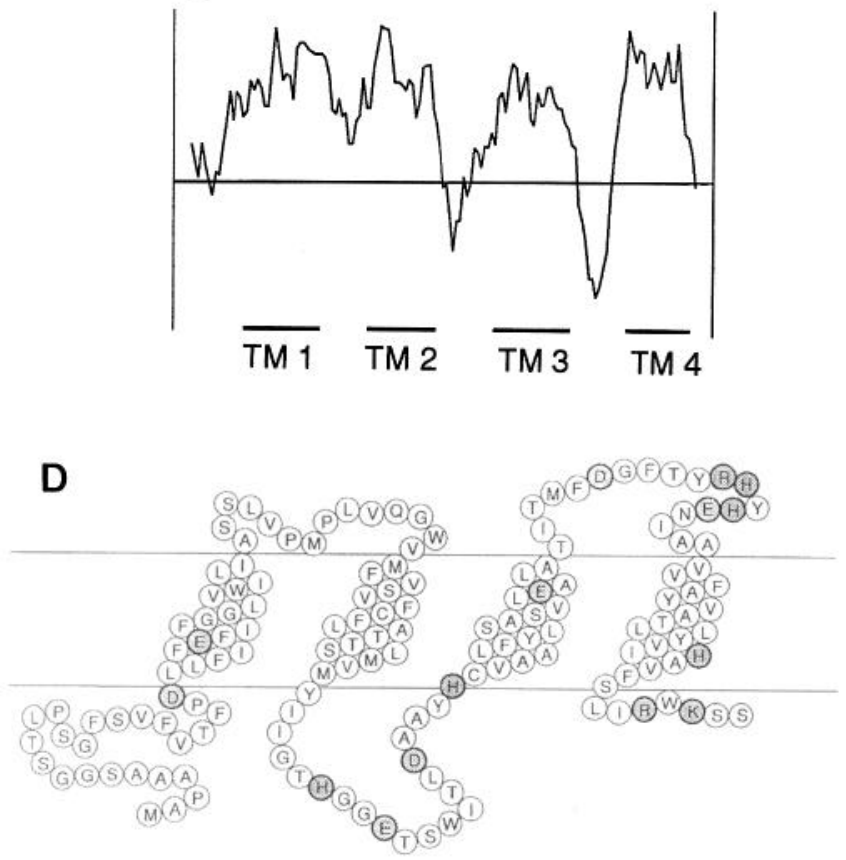

Figure 1. Continued.

phosphate buffer ( $\mathrm{pH} 7.2$ ), $7 \%$ SDS, $1 \%$ BSA, 1 mM EDTA, $20 \mu \mathrm{g} / \mathrm{ml}$ denatured salmon sperm DNA (Mahmoudi and Lin, 1989) with 0.5 to 1 million dpm of $\mathrm{P}^{32}$-labeled cDNA probe per milliliter of hybridization buffer over night at $60^{\circ} \mathrm{C}$. Filters were washed 3 times in $0.1 \times \mathrm{SSC}$, $0.1 \% \mathrm{SDS}$ at $60^{\circ} \mathrm{C}$ and subsequently exposed to Kodak XAR x-ray film at $-80^{\circ} \mathrm{C}$ with intensifying screen. $\mathrm{P}^{32}$-labeled cDNA probes were generated by random hexamer priming (Boehringer Mannheim kit).

In situ hybridization with digoxigenin-labeled cRNA probes. Synthetic riboprobes (cRNA) were generated from the whole sequence of the Bluescript containing cDNA inserts from both sides with $\mathrm{T} 3$ or T7 RNA polymerase, leading to antisense and sense (control) cRNA probes. The labeled cRNA probes were then alkali hydrolyzed to an average length of $200-400$ bases. Digoxigenin-labeled antisense and sense CRNA probes were tested in Northern analysis for their specificity. In situ hybridization was performed on cryosections ( $15 \mu \mathrm{m}$ thick) of fresh frozen tissue according to the protocol of Schaeren-Wiemers and Gerfin-Moser (1993). The color reaction time for the alkaline phosphatase reaction was about $18 \mathrm{hr}$ (except for $2 \mathrm{~d}$ in newborn tissue).

Preparation of anti-rMAL antiserum. Based on the predicted primary amino acid sequence of rMAL (NS 3), two peptide sequences were selected from the two possible hydrophilic regions: peptide 1, HGGETSWITLDAAYH (amino acids 79-93), and peptide 2, MFDGFTYRHYHEN (amino acids 114-126). Synthesis of peptides and immunization of rabbits (two rabbits for each peptide) were performed using the MAP method (Posnett et al., 1988; Tam, 1988) by Research Genetics (Huntsville, AL).

Immunohistochemistry. Immunohistochemistry for the rMAL protein was performed on $4 \%$ paraformaldehyde-fixed tissue. Serial sections ( 25 $\mu \mathrm{m}$ thick) were cut in the sagittal plane for the brain and in the transversal plane for the spinal cord and sciatic nerve. Sections were immersed for $25 \mathrm{~min}$ in ice-cold $95 \%$ ethanol, 5\% acidic acid, rehydrated into phosphate buffer (PBS) and residual protein binding sites were blocked by a
$1 \mathrm{hr}$ incubation in PBS containing $0.2 \%$ BSA-C, $0.1 \%$ cold water fish gelatine (both from Aurion, Wageningen, NL), $2.5 \%$ normal goat serum, and $0.05 \%$ saponin (Sigma). Anti-peptide 2 antiserum was used at a dilution of 1:200 and incubated overnight at $4^{\circ} \mathrm{C}$. The secondary anti-rabbit biotinylated antibody (Vector) was used at a dilution of 1:100 and incubated for $2 \mathrm{hr}$ at room temperature. The staining patterns were revealed with the $\mathrm{ABC}$ method (Vector ABC kit) according to the manufacturer's instructions, with diaminobenzidine (DAB) as the chromogen. Sections were embedded and analyzed on an Olympus Vanox-T microscope.

For immunohistochemistry after in situ hybridization a polyclonal antibody against MBP (kindly provided by Dr. J.-M. Matthieu, Lausanne) was used at a dilution of $1: 250$, incubated over night at $4^{\circ} \mathrm{C}$. The secondary antibody (anti rabbit-RITC, Jackson, West Grove, PA) was used at a dilution of 1:100 and incubated for $1 \mathrm{hr}$ at room temperature. The Hoechst dye $33286(1 \mathrm{mg} / \mathrm{ml}$ in methanol, Calbiochem $)$ was diluted 1:100 and applied between the washing steps after the secondary antibody. Sections were embedded in Kaiser's gelatin (Merck) and analyzed as described above.

Immunoblot analysis. CNS myelin protein was prepared as described in Caroni and Schwab (1988) and separated on 15\% SDS-polyacrylamide gels. The gels were fixed in $40 \%$ methanol, $10 \%$ acetic acid for $10 \mathrm{~min}$, incubated for $30 \mathrm{~min}$ in $1 \%$ SDS, $48 \mathrm{~mm}$ Tris, $39 \mathrm{~mm}$ glycine, $20 \%$ methanol with several changes. The proteins were transferred to Immobilon-P membranes (Millipore) by semidry electrophoresis at room temperature for $1.5 \mathrm{hr}$ at $74 \mathrm{~V}$ in $48 \mathrm{~mm}$ Tris buffer containing $39 \mathrm{~mm}$ glycine, $0.037 \%$ SDS, $20 \%$ methanol. The membranes were rinsed in PBS, and additional protein binding sites were blocked by a $1 \mathrm{hr}$ incubation in PBS containing 3\% BSA. Anti-peptide 2 antiserum was used at a dilution of $1: 500$ and incubated overnight at $4^{\circ} \mathrm{C}$ in PBS with $3 \%$ BSA. The secondary anti-rabbit alkaline phosphatase-coupled antibody (Jackson, West Grove, PA) was used at a dilution of 1:5000 and incubated for $2 \mathrm{hr}$ at room temperature. After three rinses of PBS the bound alkaline phosphatase was localized using BCIP (5-bromo-4-chloro-3-indolylphosphate $p$-toluidine) and NBT (nitroblue tetrazolium chloride) as substrates.

\section{Results}

Isolation of rMAL cDNA clone

We differentially screened a postnatal day 16 rat spinal cord cDNA library for clones that hybridized with a probe derived from normal spinal cord but did not hybridize with a probe derived from spinal cord which was free of oligodendrocytes (Schaeren-Wiemers et al., 1995). The known myelin genes MBP, PLP, MAG, and CNPase were also subtracted. Cross-hybridization analysis and Northern blot analysis revealed several genes which were either exclusively expressed by oligodendrocytes or by oligodendrocytes and Schwann cells. One of these cDNA clones, denominated NS 3 , revealed a $2.2 \mathrm{~kb}$ transcript which is expressed in spinal cord and in sciatic nerve. The $2187 \mathrm{bp}$ cDNA sequence contains a 47 bp untranslated region at the $5^{\prime}$ end, a 461 bp open reading frame coding for a 153 amino acid protein, and a 1681 bp $3^{\prime}$ noncoding region (Fig. 1A). Comparison of the cDNA sequence to the EMBL GeneBank data base showed that the NS 3 mRNA is likely to be the rat homolog of the previously described gene MAL which was isolated from a human T-lymphocyte cell line (Alonso and Weissman, 1987). Both sequences show an overall homology of $80 \%$ at the nucleotide level in the open reading frame and the 5' untranslated region. The human MAL mRNA has a size of $1 \mathrm{~kb}$ and lacks the $1.2 \mathrm{~kb} 3^{\prime}$ noncoding region of the rat sequence. The two predicted protein sequences are $89 \%$ identical and by adding conservative exchanges $95 \%$ similar (Fig. 1B). Therefore, NS 3 is denominated rat MAL (rMAL).

\section{Structure of rat MAL protein in relation to human $M A L$ protein and other four-hydrophobic domain proteins}

Analysis of the complete deduced amino acid sequence of the open reading frame of the $\mathrm{rMAL}$ clone predicts a molecular mass for the rMAL polypeptide of $16.8 \mathrm{kDa}$. Based on hydro- 

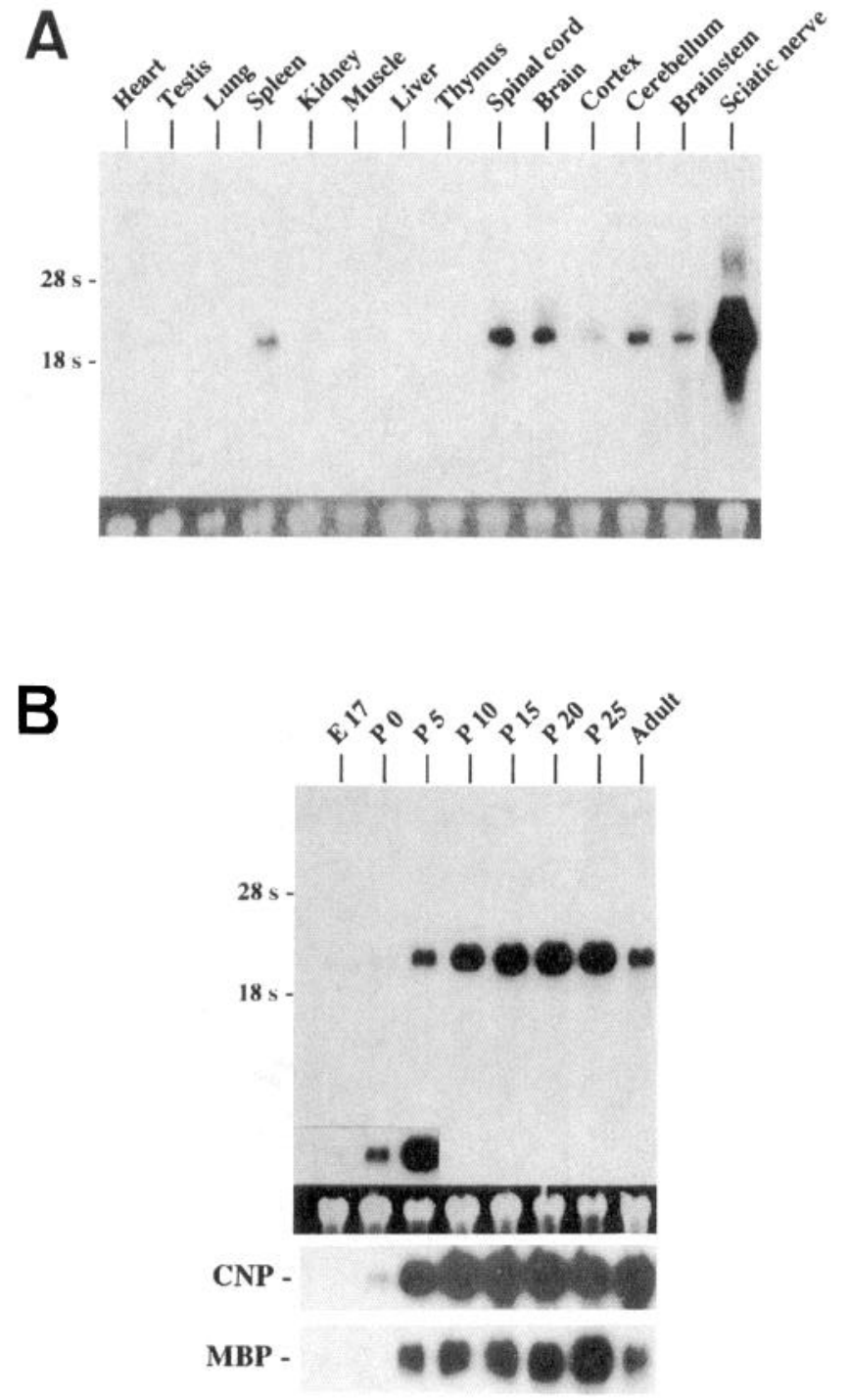

Figure 2. Expression pattern of rMAL mRNA in different adult tissues and during spinal cord development. Northern blots of total cellular RNA ( $5 \mu \mathrm{g} / \mathrm{lane}$ ) were examined for rMAL expression in tissues isolated from adult rats $(A)$ (except for sciatic nerve which was postnatal day 10 ) and for spinal cord at various stages of development $(B)$ (from embryonic stage E17 to adulthood). Transcripts corresponding to rMAL are highly expressed in the nervous system; spleen and kidney show low expression. In spinal cord development rMAL mRNA is highly expressed in the first 3 postnatal weeks. Enclosure shows a longer exposure time of the autoradiograph. Migration of the ribosomal bands is indicated on the left. The panel at the bottom shows the ethidium bromide staining of the 28 s ribosomal RNA as a loading control. phobicity plots and secondary structure prediction the amino acid residues $25-41,55-71,93-109$, and 129-145 represent putative transmembrane segments (Fig. $1 A, C$ ). The $\mathrm{N}$-terminal sequence does not contain a cleavable signal sequence. There is no consensus site for $\mathrm{N}$-linked glycosylation. This is supported by the fact that in vitro translation from the full length cDNA revealed a discrete band of an apparent mass of $16 \mathrm{kDa}$ on SDS polyacrylamide gels (data not shown). The apparent molecular weight was not altered by adding microsomal membranes allowing potential posttranslational modifications such as cleaving of signal peptide and glycosylation (data not shown). Figure $1 D$ shows the proposed model for the orientation of the rMAL protein which is adapted from the model of Alonso and Weissman (1987) for human MAL. The first and third putative transmembrane domain contain charged amino acids, a feature which is typical for membrane proteins forming pores such as gap junction proteins of the connexin superfamily (for review, see Bennett et al., 1991) and for ion channels such as the neurotransmitter receptor superfamily (for review, see Unwin, 1989). These two domains of the rat and human MAL protein are highly conserved (97\% identical) whereas the other two domains are less conserved ( $80 \%$ identical; Fig. $1 B$ ). Although structural similarities of rMAL to PLP, PMP-22, and connexin are evident, no significant sequence homologies could be detected, either to this set of proteins, or to other proteins included in the database.

\section{rMAL MRNA is mainly expressed in the nervous system and peaks during myelination}

Northern analysis of different tissues of the adult rat demonstrated that MAL mRNA is predominantly expressed in the highly myelinated regions of the nervous system such as spinal cord, brainstem and developing sciatic nerve, with lower expression levels in the cerebellum and cerebral cortex (Fig. 2A). A weaker signal could be seen in spleen and in kidney. No detectable signal was found in heart, testis, lung, muscle, liver, and thymus.

To determine the developmental time course of rMAL mRNA expression, Northern blot analysis of different developmental stages during spinal cord development was performed (Fig. $2 B$ ). rMAL transcripts became detectable first after birth and were most highly expressed during the initial three postnatal weeks, when oligodendrocytes are very active in myelinating axons. In the adult spinal cord rMAL mRNA was expressed at a lower level. This expression pattern corresponded to the expression pattern of transcripts of other myelin-associated proteins such as CNPase, MBP (Fig. 2B) or PLP (Zeller et al., 1984; Hudson et al., 1987; Jordan et al., 1989). In the developing sciatic nerve rMAL mRNA was much more highly expressed than in the CNS with an expression level comparable to that of MBP mRNA (Fig. 2; Schaeren-Wiemers et al., 1995).

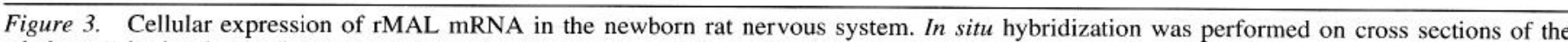

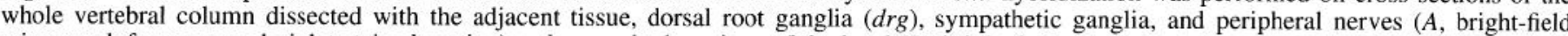

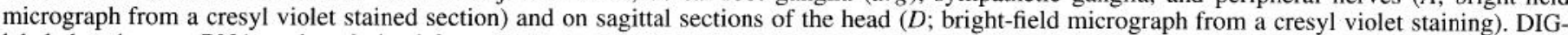

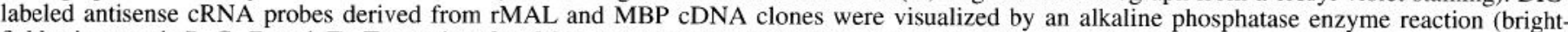

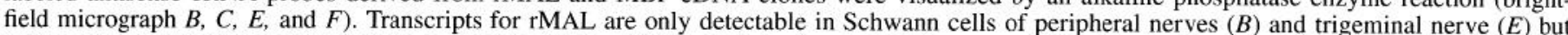

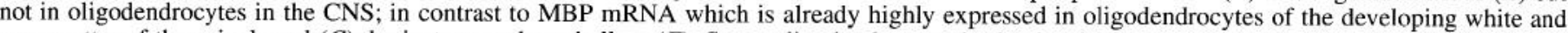

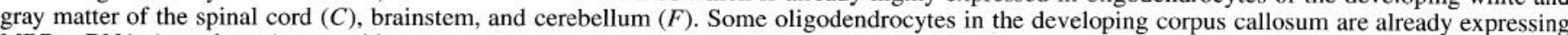

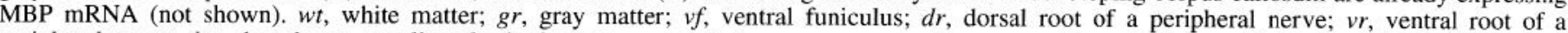

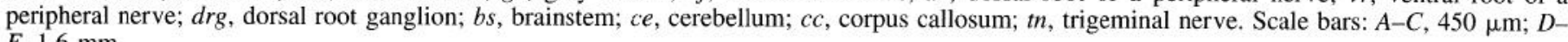
$F, 1.6 \mathrm{~mm}$. 
PO SPINAL CORD

PO HEAD

CV
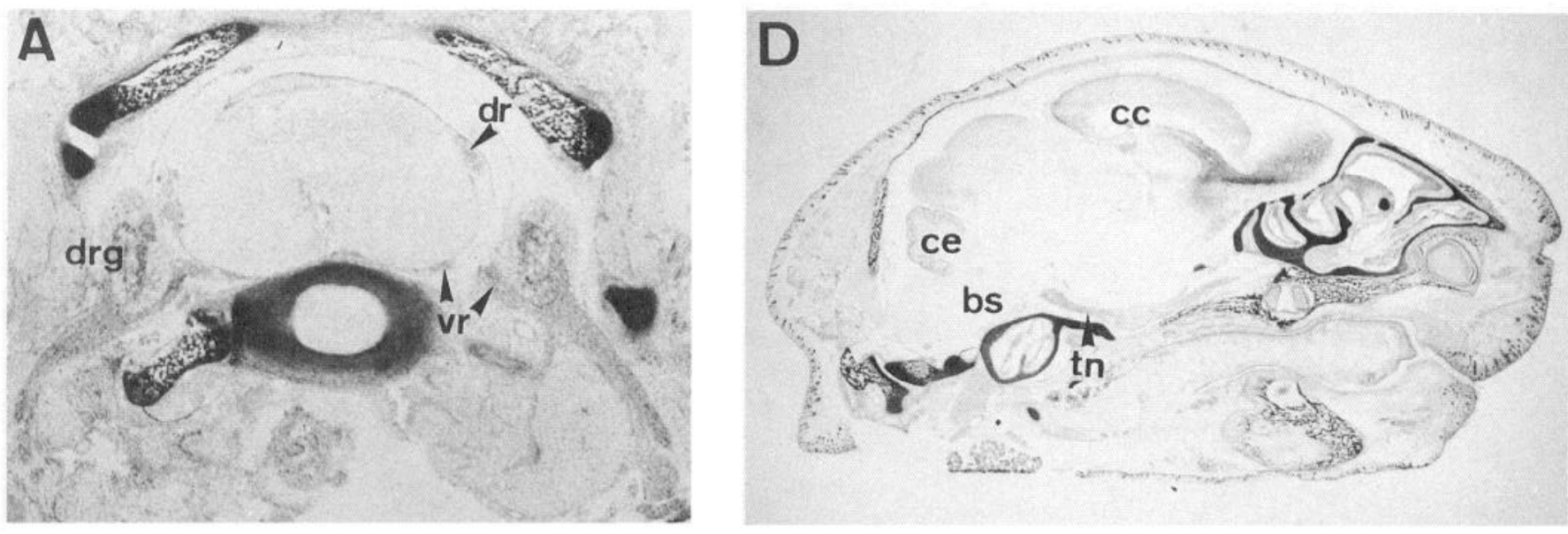

r MAL

B

E
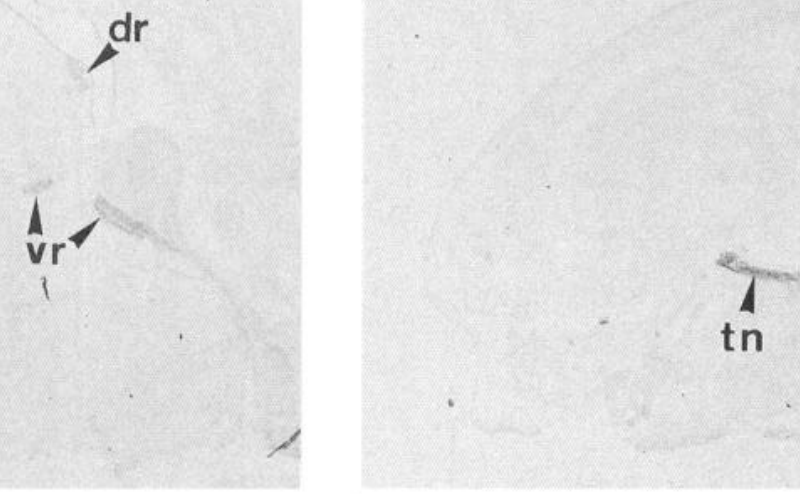

MBP

C

drg ${ }_{v r}{ }_{w t}^{g r}$

$F$

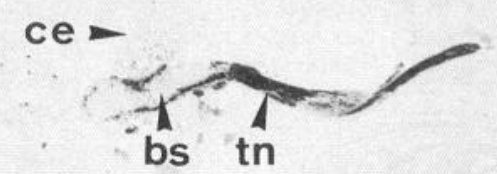


In the nervous system, rMAL MRNA is exclusively expressed by oligodendrocytes and Schwann cells

Myelin formation starts at birth in the ventral and dorsal funiculi in the cervical part of the rat spinal cord (Rozeik and Keyserlingk, 1987; Schwab and Schnell, 1989). Myelination in the PNS starts shortly before birth (Mirsky and Jessen, 1990). To determine the localization of rMAL mRNA and its expression pattern during development in oligodendrocytes and Schwann cells, we performed in situ hybridization on sections of brain, spinal cord, and peripheral nerves of animals of various ages. The rMAL mRNA expression pattern was compared to that of MBP mRNA, which is already expressed before birth (unpublished data), and MBP protein (by immunofluorescence), a marker for myelination that is expressed after birth (Rozeik and Keyserlingk, 1987; Schwab and Schnell, 1989).

\section{At birth, rMAL mRNA is expressed in Schwann cells but not in oligodendrocytes}

In situ hybridization was performed on cross sections of the vertebral column dissected with the adjacent muscle tissue, dorsal roots, sympathetic ganglia, and their peripheral nerves of newborn rat pups (Fig. 3A). MBP mRNA is already expressed in oligodendrocytes in the ventral and dorsal white matter and, in some cells, in the gray matter of the cervical segments of the spinal cord (Fig. 3C), whereas no labeled cells could be detected with the rMAL cRNA probe (Fig. $3 B$ ). At this developmental stage, only traces of the glycolipid antigen $\mathrm{O} 1$ and of MBP immunoreactivity, both specifically expressed by oligodendrocytes and Schwann cells (Sommer and Schachner, 1981; Colman et al., 1982), were detectable in a small region of the ventral funiculus (Rozcik and Keyscrlingk, 1987; Schwab and Schncll, 1989). The first oligodendrocytes expressing rMAL mRNAs could be detected in the ventral funiculi of half-day-old animals.

In the PNS, transcripts for rMAL and MBP were detectable in Schwann cells of the ventral and dorsal roots of the newborn spinal cord (Fig. $3 B, C$, respectively).

In situ hybridization on sagittal sections of a newborn rat head (Fig. 3D) demonstrated that rMAL InRNA was not detectable in the newborn CNS (Fig. 3E), in contrast to MBP mRNA which is expressed in the brainstem, in the developing white matter of the cerebellum and in a few single cells in the corpus callosum (Fig. 3F).

In the trigeminal nerve, as in the cervical spinal roots, rMAL was detectable over the whole nerve with a decreasing expression level towards the whisker pad (Fig. 3E), similar to, although at lower levels than MBP mRNA (Fig. $3 F$ ).

\section{At P5, rMAL mRNA is highly expressed in the myelinating fiber tracts of the nervous system}

In situ hybridization for $\mathrm{MAL}$ and MBP mRNA was combined with MBP immunofluorescence on cross sections of postnatal day 5 spinal cord (Fig. $4 A-C$ ). Similar to P0, rMAL was expressed by cells in the developing CNS white matter and spinal roots (Fig. $4 B$ ). The number of rMAL-positive cells was clearly lower than that of MBP-positive cells (Fig. $4 C$ ), suggesting that the expression of the rMAL gene follows that of MBP.

In sagittal brain sections, rMAL mRNA was detectable in the developing white matter of brainstem and cerebellum (Fig. $4 D$ ), regions where myelination is known to be most advanced ( $\mathrm{Ja}$ cobson 1963). In corpus callosum, rMAL mRNA could not be detected (Fig. $4 F$ ), whereas MBP mRNA is already highly expressed (Fig. 4G).

\section{At P15, rMAL mRNA is highly expressed in all myelinating regions of the nervous system}

In postnatal day 15 spinal cords, expression of the oligodendrocyte-specific genes such as MBP and rMAL was most prominent as shown by Northern blot analysis (Fig. 2B; Zeller et al., 1984). In situ hybridization showed that $\mathrm{rMAL}$ and MBP mRNAs were highly expressed in oligodendrocytes and in Schwann cells (Schaeren-Wiemers et al., 1995). Again, however, the expression of rMAL seemed to lag behind that of MBP; In P15 brain sections MBP $m R N \Lambda$ was already detectable in regions which are less myelinated such as the granule cell layer of the cerebellum and the cerebral cortex, whereas transcripts of rMAL were only detectable in myelinating fiber tracts of the white matter (not shown).

\section{In the adult spinal cord, rMAL $m R N A$ is more highly expressed in oligodendrocytes of the gray matter than of the white matter}

Interestingly, in situ hybridization in the spinal cord demonstrated that the expression of rMAL mRNA is higher in oligodendrocytes of the gray matter than of the white matter (Fig. 5A,C) in contrast to MBP mRNA (Fig. $5 B$ ) and several other oligodendrocyte-specific genes (data not shown) that are more highly expressed in oligodendrocytes of the white matter. In the brain the expression level of rMAL transcripts was similar in white and gray matter: oligodendrocytes in the cerebral cortex and in the granule cell layer of the cerebellum were as intensely labeled with the rMAI , probe as oligodendrocytes lying in the neighboring myelinated fiber tracts (Fig. $5 D, F$ ), comparable to the pattern seen for MBP mRNA (Fig. $5 E, G$ ).

\section{rMAL-protein is localized in PNS and CNS myelin}

To investigate the cellular localization of the rMAL protein, polyclonal rabbit antisera were raised against peptides derived from the rMAL amino acid sequence. The best results were obtained with an anti-peptide antiserum directed against amino acid 114-126 forming the third putative extracellular domain of the rMAL protein. With this serum, a specific band was obtained in the $18-20 \mathrm{kDa}$ range on immunoblots from CNS myelin proteins

Figure 4. Expression pattern of rMAL and MBP transcripts at postnatal day 5. In situ hybridization was performed on cross sections of P5 spinal cord for rMAL ( $B$, combined with the nuclear stain Hoechst, bright-field micrograph) and MBP mRNA ( $C$. bright-field micrograph) and combined with immunofluorescence for MBP ( $A$, rhodamine-fluorescence, dark-field micrograph). $A-C$ show the ventral horn of the cervical part of the developing spinal cord. Transcripts of rMAL are mainly localized in the white matter of the spinal cord $(B)$, in contrast to MBP transcripts which are already also highly expressed in oligodendrocytes of the gray matter $(C)$. Oligodendrocytes which are expressing rMAL mRNA are also positive for MBP immunofluorescence ( $A$ and $B$, arrow). In situ hybridization on sagittal sections of P5 brain shows that rMAL is only expressed in the myelinating regions of brainstem and cerebellum $(D)$ in contrast to MBP mRNA which is already detectable in the developing fiber tracts of brainstem, cerebellum $(E)$, and corpus callosum $(G)$. At this age, rMAL mRNA is not detcctable in corpus callosum $(F)$. $b s$, Brainstem; ce, cerebellum; $c c$, corpus callosum; $w t$, white matter; $c x$, cerebral cortex. Scale bar: $A-C, F$, and $G, 130 \mu \mathrm{m} ; D$ and $E, 460 \mu \mathrm{m}$. 
P5
A. MBP IR
B. $r M A L$
C. MBP
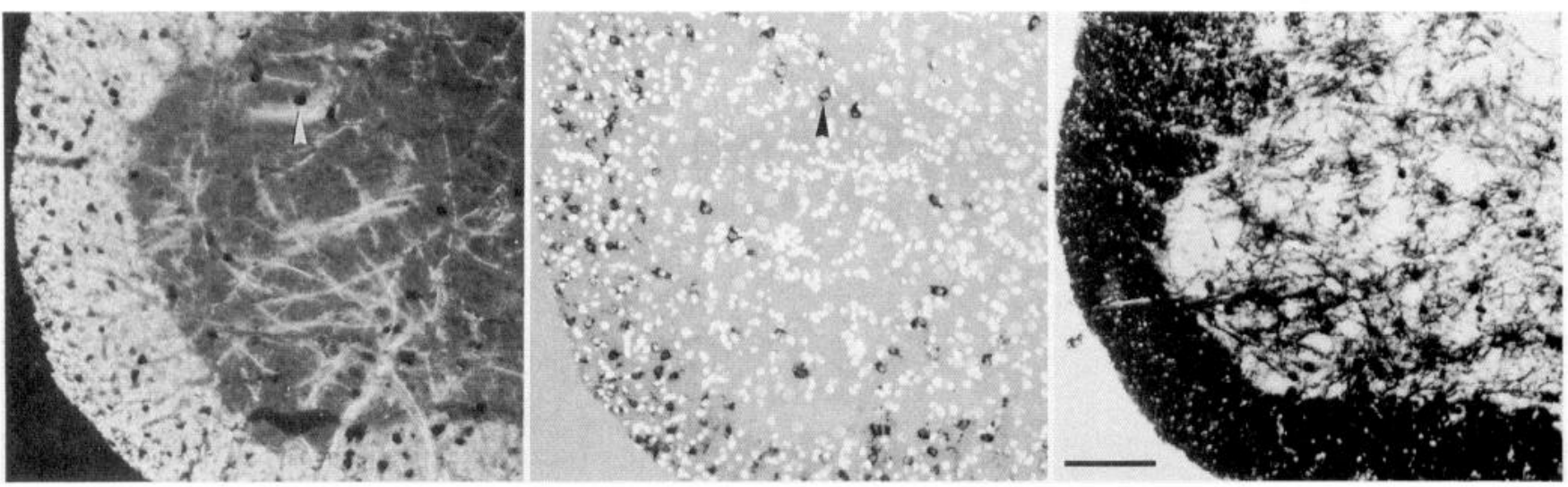

D. r MAL

\section{E. MBP}

ce

F. r MAL

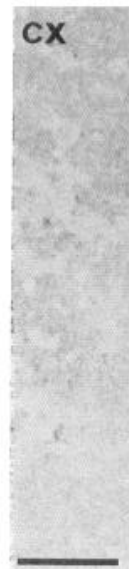

cC

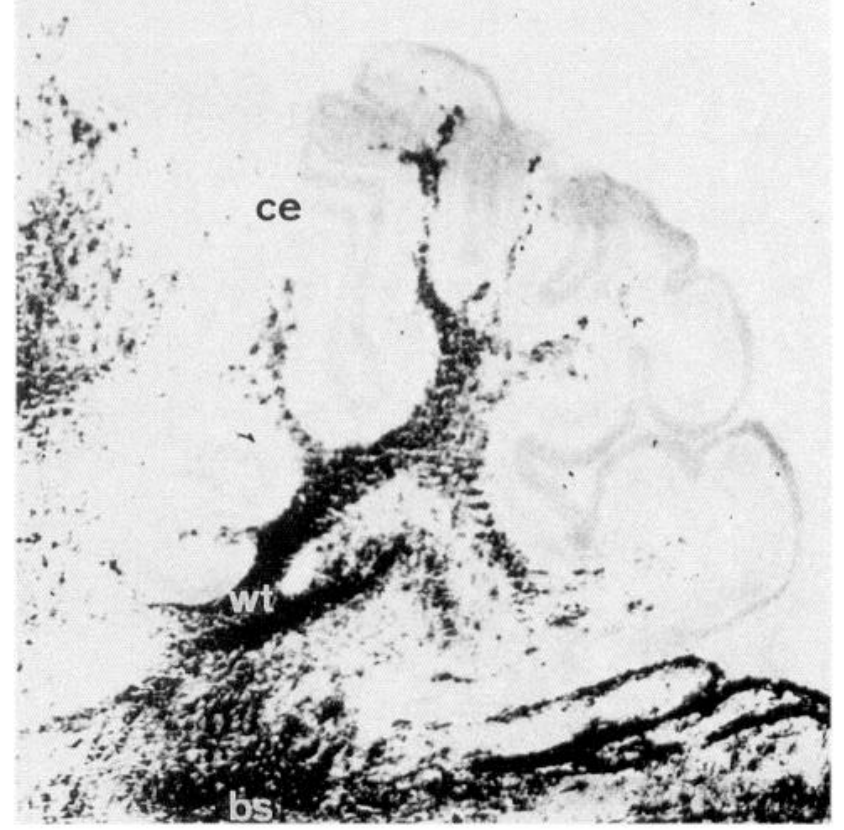

\section{G. MBP}

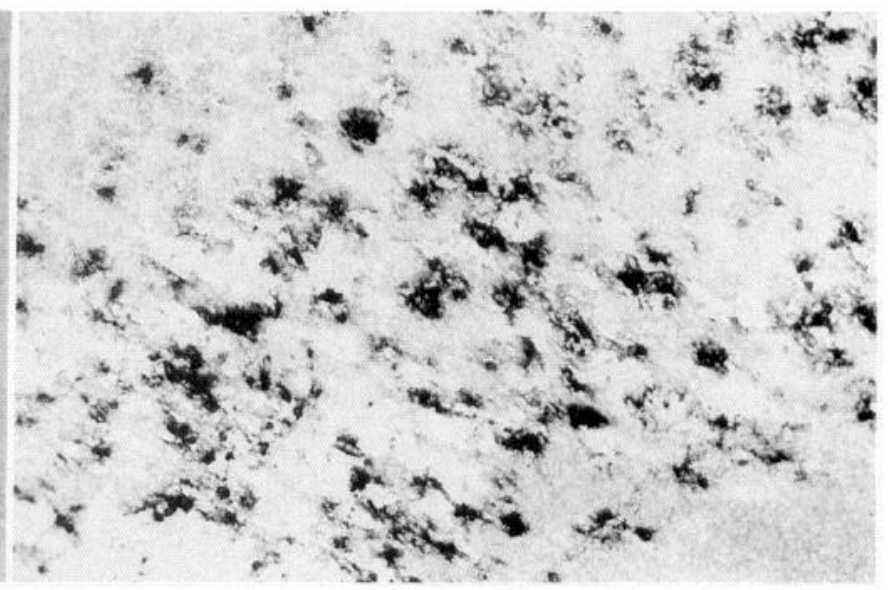



A. r MAL
B. MBP
C. $r M A L$
ADULT

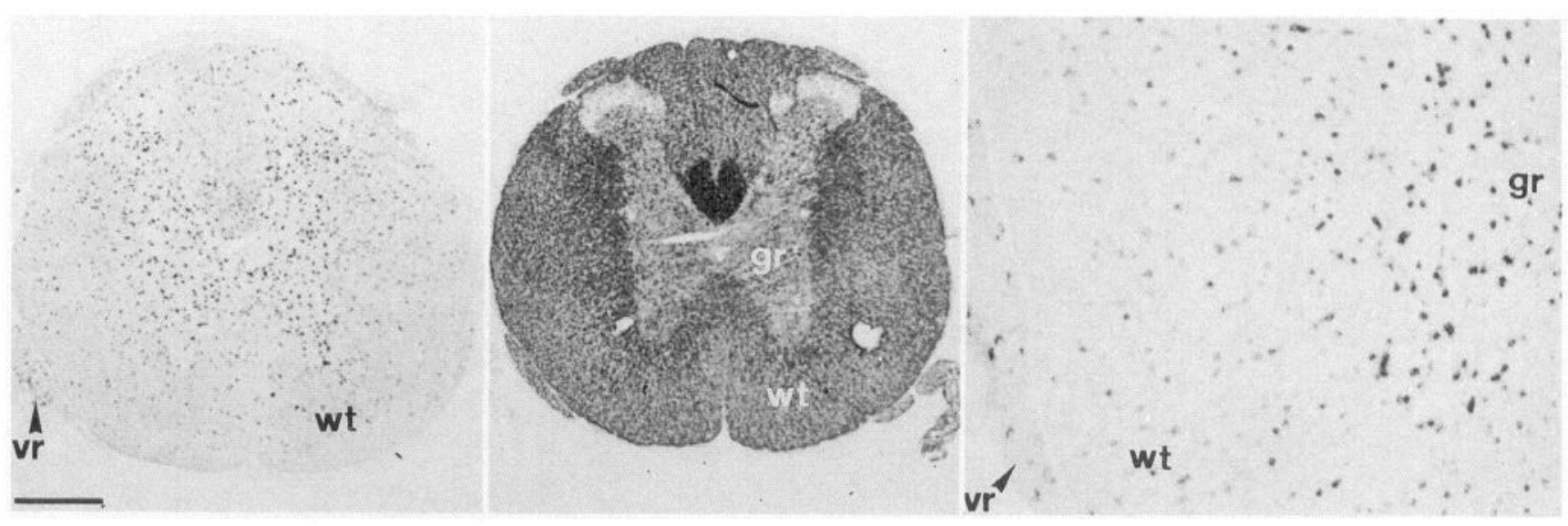

D. rMAL

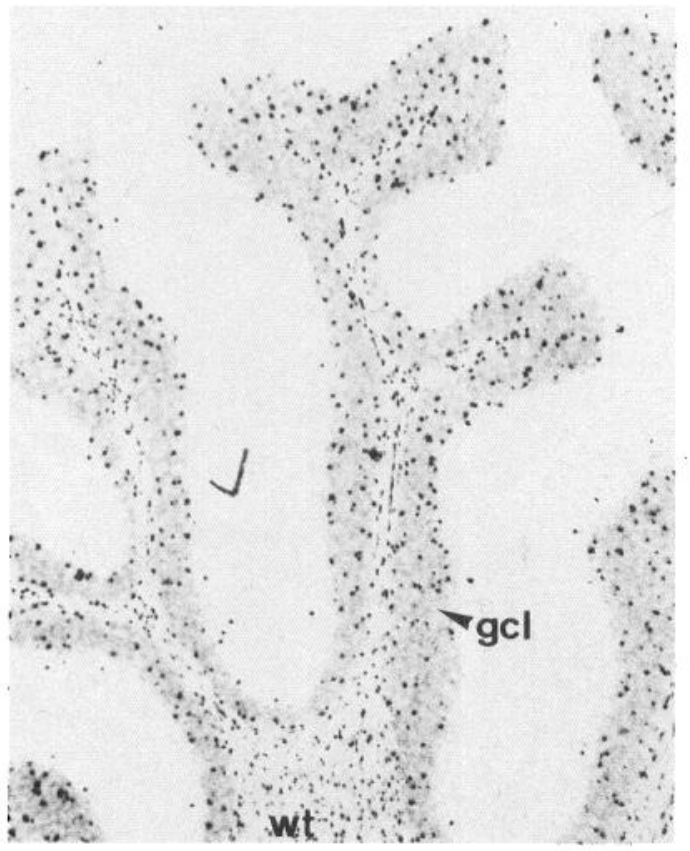

F. rMAL

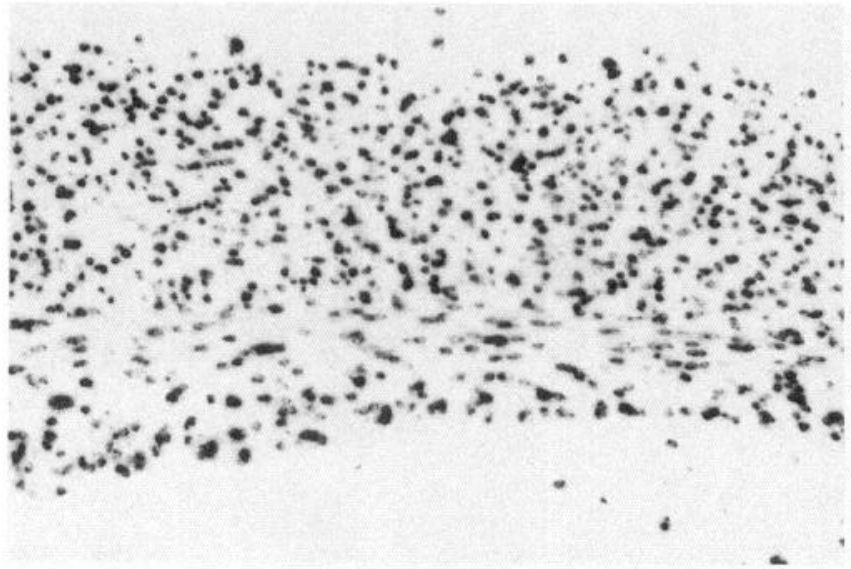

\section{E. MBP}

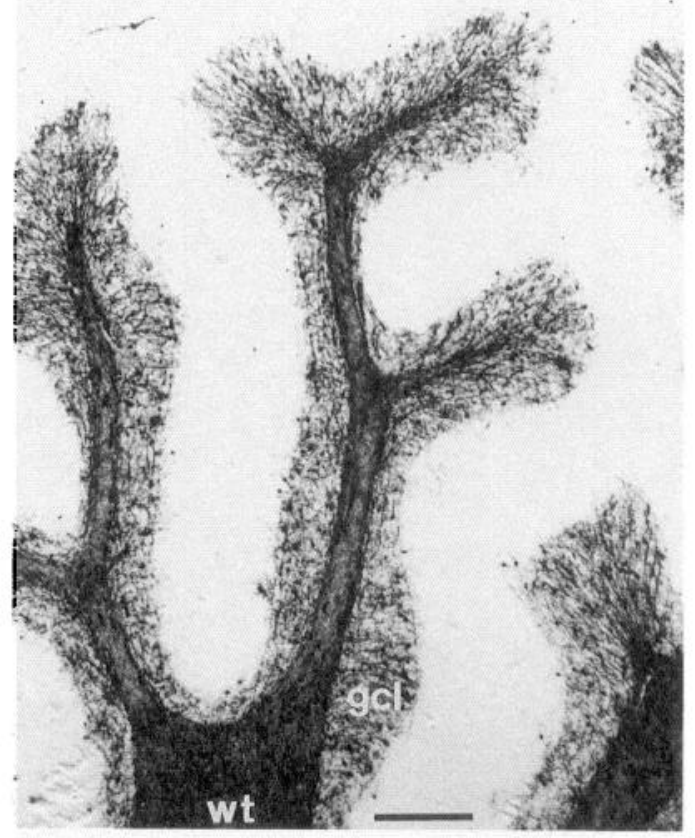

\section{G. MBP}

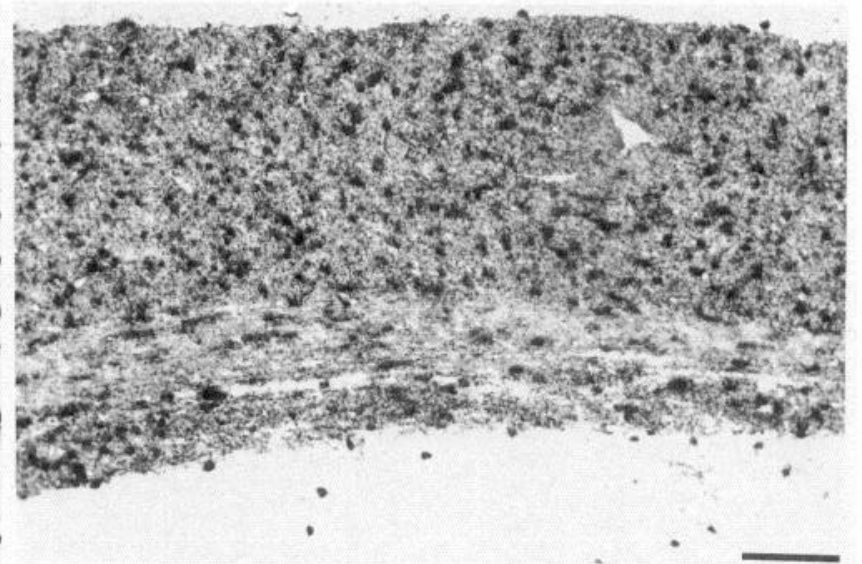

Figure 5. Expression pattern of rMAL and MBP transcripts in the adult nervous system. In situ hybridization was performed on cross sections of adult spinal cord for $\operatorname{rMAL}(A, C)$ and for MBP mRNA ( $B$, bright-field micrograph). A highest expression was found for rMAL in oligoden 
(Fig. 6). This antiserum was then used for immunohistochemistry on frozen sections of nervous tissue (Figs. 7, 8).

In spinal roots, rMAL immunoreactivity was observed in the myelin sheaths (Fig. 7A). The staining pattern corresponded to the staining pattern of MBP (Fig. $7 B$ ). The differences in staining intensity of different nerve fibers probably reflect differences in myelination or antibody penetration, since similar results were obtained with an anti-MBP staining.

On cross sections of adult spinal cord, highest rMAL immunoreactivity was detected in the myelinated regions, for example, in the dorsal funiculus (Fig. 7D). In comparison to MBP, rMAL immunoreactivity was higher in the PNS part of the spinal roots than in the part myelinated by oligodendrocytes (Fig. 7D,E).

On sagittal sections of adult brain, rMAL immunoreactivity was localized in the myelinated regions as exemplified by the cerebellum (Fig. 8A). Compared to an anti-MBP antiserum, the immunoreactivity for the rMAL anti-peptide antiserum was weaker (Fig. 8B).

\section{Discussion}

In this report, we describe the characterization of a rat cDNA that encodes an new myelin protein with four putative transmembrane domains. This cDNA is called rMAL since it is most probably the rat homolog of a human cDNA (MAL) isolated from human T-cell lines (Alonso and Weissman, 1987). The rMAL gene is predominantly expressed in myelinated areas of the CNS and PNS, with a higher expression level in the PNS. The onset of rMAL expression correlates well with myelin formation by oligodendrocytes and Schwann cells: the rMAL gene starts to be expressed just before birth in Schwann cells and after birth in oligodendrocytes of brainstem and spinal cord. The developmental expression pattern of rMAL transcripts corresponds to that of the glycolipid marker O1 and of MBP but is delayed compared to MBP mRNA expression which is already detectable in Schwann cells at embryonic day E17.5 and in oligodendrocytes before birth (own observations).

In comparison to other recently identified oligodendrocyteand myelin-specific genes (Schaeren-Wiemers et al., 1995), rMAL is a late gene in developing oligodendrocytes. Most of the myelin genes studied so far including MBP are more highly expressed in oligodendrocytes of the white matter than of the gray matter (Jordan et al., 1989; our own observations). Interestingly, the rMAL gene appears to be an exception: in the oligodendrocytes of the gray matter of the adult spinal cord, the expression level of the rMAL gene is consistently higher than in the adjacent white matter regions.

Evidence that the rMAL protein is a myelin protein was obtained by immunohistochemistry and immunoblots using a rMAL-specific anti-peptide antiserum. rMAL immunoreactivity could be localized in the myelinated areas in the brain, in spinal cord, and in myelin sheaths of spinal roots. The levels of rMAL protein in the PNS were higher than in the CNS similar to the levels of rMAL mRNA. Compared to MBP, a major myelin protein which constitutes up to $30 \%$ of the total CNS myelin protein, staining for rMAL was clearly weaker. Results from immunoblots show rMAL immunoreactivity in a $18-20 \mathrm{kDa}$ pro-

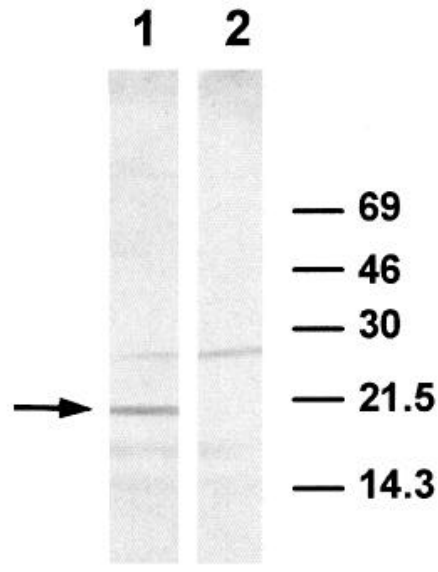

Figure 6. Immunoblots of rat CNS myelin proteins with the antirMAL peptide antiserum. On immunoblots of CNS myelin proteins (15\% SDS-PAGE), a band at $18-20 \mathrm{kDa}$ (arrow) became visible at a 1:500 dilution of the antiserum (lane 1). Preimmune serum gave no detectable staining in this region (lane 2). The same unspecific bands were present both in the immune and preimmune serum. Position of the molecular weight markers is indicated on the right.

tein band which was not detected by the preimmune serum. As it is known for other myelin proteins, rMAL was enriched in the myelin fractions (unpublished observation).

\section{Relationship of rat MAL to the human gene $M A L$}

Sequence analysis of the NS 3 cDNA clone showed a very high homology to a human gene called MAL that was isolated by subtractive hybridization of two different human T-cell lines (Alonso and Weissman, 1987). Within the open reading frame the two cDNAs show a $89 \%$ identity on the amino acid level and $80 \%$ identity on the nucleotide level. At the $3^{\prime}$ nontranslated end, however, rat MAL has a $1.2 \mathrm{~kb}$ extension, which is absent in human MAL. The human MAL gene is expressed in leukemic T-cell lines that express both the T-cell receptor and the T11 antigen, and in normal mature T-cell clones (Alonso and Weissman, 1987). Genomic Southern analysis with rMAL on chromosomal rat DNA revealed a similar hybridization pattern as it has been shown with the human MAL probe hybridized on rat chromosomal DNA (data not shown, Alonso et al., 1988). Therefore, it is very likely that NS 3 is the rat homolog to human MAL. For this reason, we propose to call this protein rMAL, standing for rat Myelin And Lymphocyte protein.

Northern analysis of adult human tissues showed that MAL is expressed in thymus, but not in colon, liver, adrenal gland, and in cells from B-cell lines (Alonso and Weissman, 1987). Our data show that the rMAL gene is predominantly expressed in the nervous system, especially during myelination. In spleen and kidney rMAL transcripts could also be detected but at a much lower level. Since Northern analysis for MAL has not been performed in those tissues from humans, a direct comparison can not be made.

drocytes of the gray matter than of the white matter $(C)$. In situ hybridization on sagittal sections of the cerebellum $(D)$ or the corpus callosum $(F)$ show that rMAL mRNA is highly expressed in oligodendrocytes of the white and of the gray matter. $E$ and $G$, Serial sections stained for MBP mRNA. $w t$, white matter; $g r$, gray matter; $g c l$, granule cell layer; $v r$, ventral root. Scale bar: $A, B, D$, and $E, 530 \mu \mathrm{m} ; C, 190 \mu \mathrm{m} ; F$ and $G, 116$ $\mu \mathrm{m}$. 


\section{r MAL}
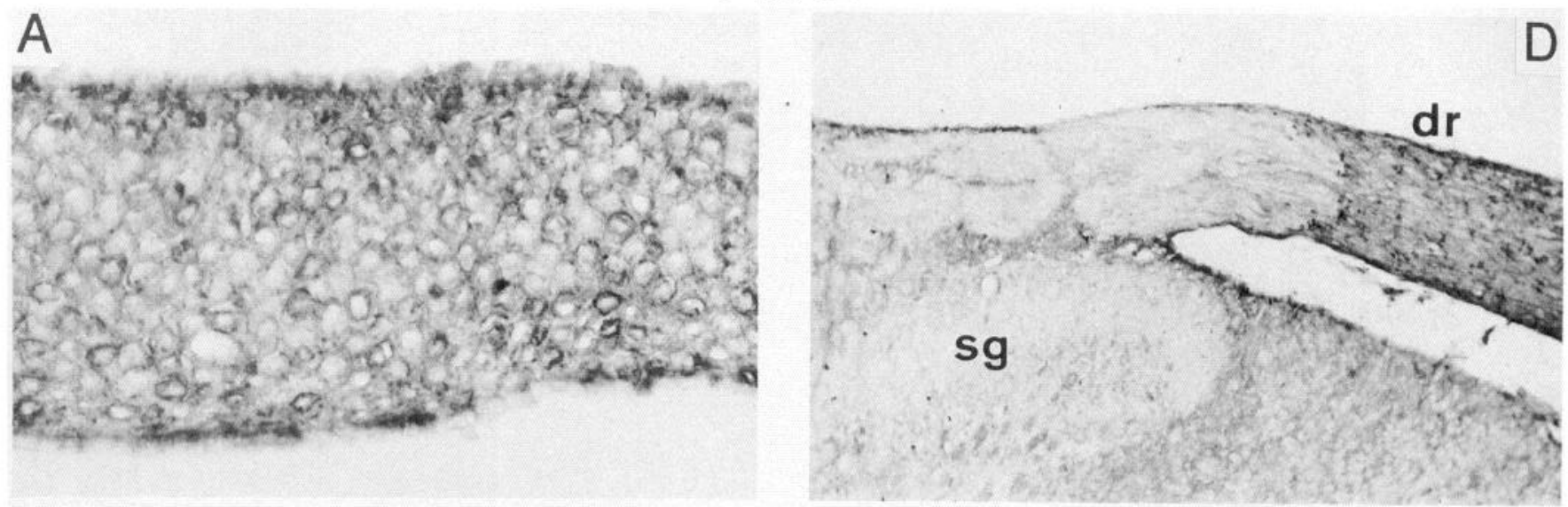

\section{MBP}
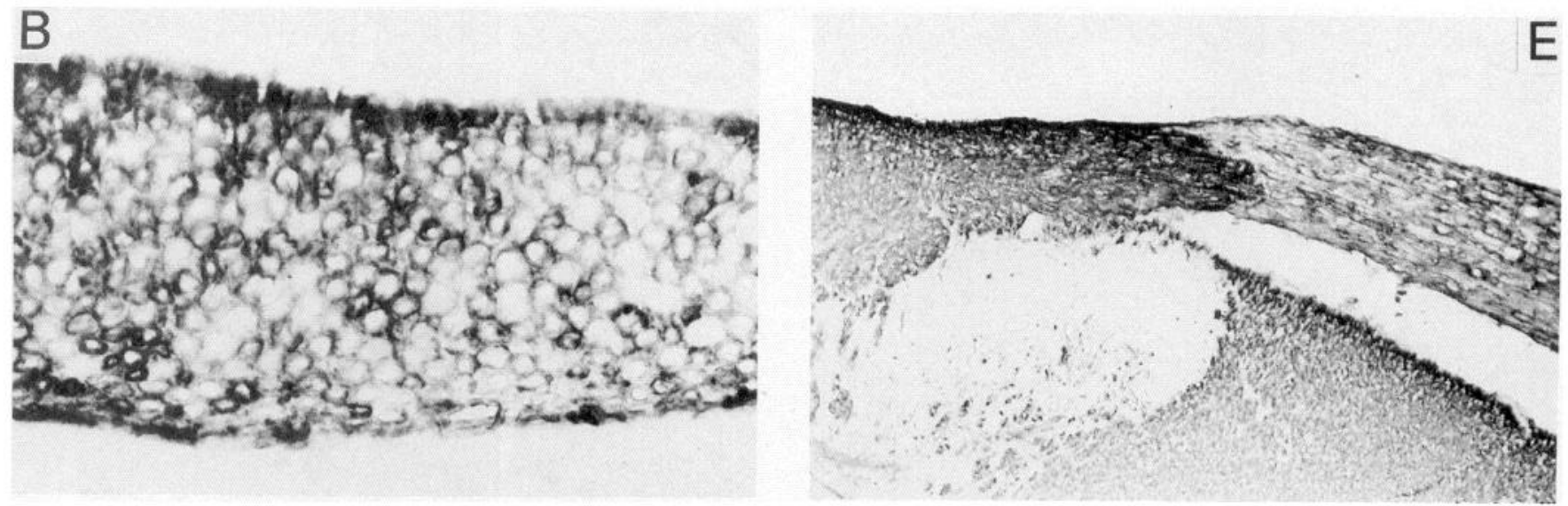

\section{Pre}

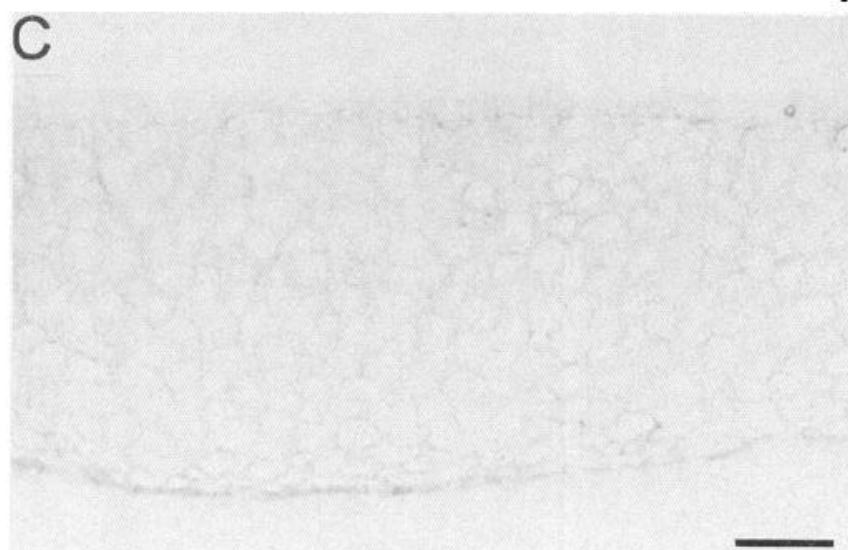

Figure 7. Localization of rMAL protein in spinal roots and spinal cord by immunohistochemistry. Immunoperoxidase detection of rMAL protein was performed with anti-rMAL peptide antiserum on cross sections of spinal roots $(A$; bright-field micrograph) and on transversal sections of the spinal cord $(D$; dorsal horn) from adult animals. In the spinal roots, the antiserum stained the myelin sheath of single axons $(A)$. The staining intensity varied among myelinated nerve fibers and is similar to the immunoreactivity for MBP $(B)$. In the spinal cord, rMAL immunoreactivity is detectable in all myelinated regions $(D)$, but not in unmyelinated regions such as the substantia gelatinosa $(\mathrm{sg})$. The transition zone of the CNS and PNS in the spinal root clearly shows that rMAL immunoreactivity is higher in the PNS $(D)$, in contrast to MBP immunoreactivity which is higher in the CNS $(E)$. Preimmune serum did not show any detectable staining in dorsal roots $(A)$ or in the spinal cord $(D)$. Scale bar: $A-C, 300$ $\mu \mathrm{m} ; D-F, 780 \mu \mathrm{m}$. 


\section{A. $\mathrm{rMAL}$}
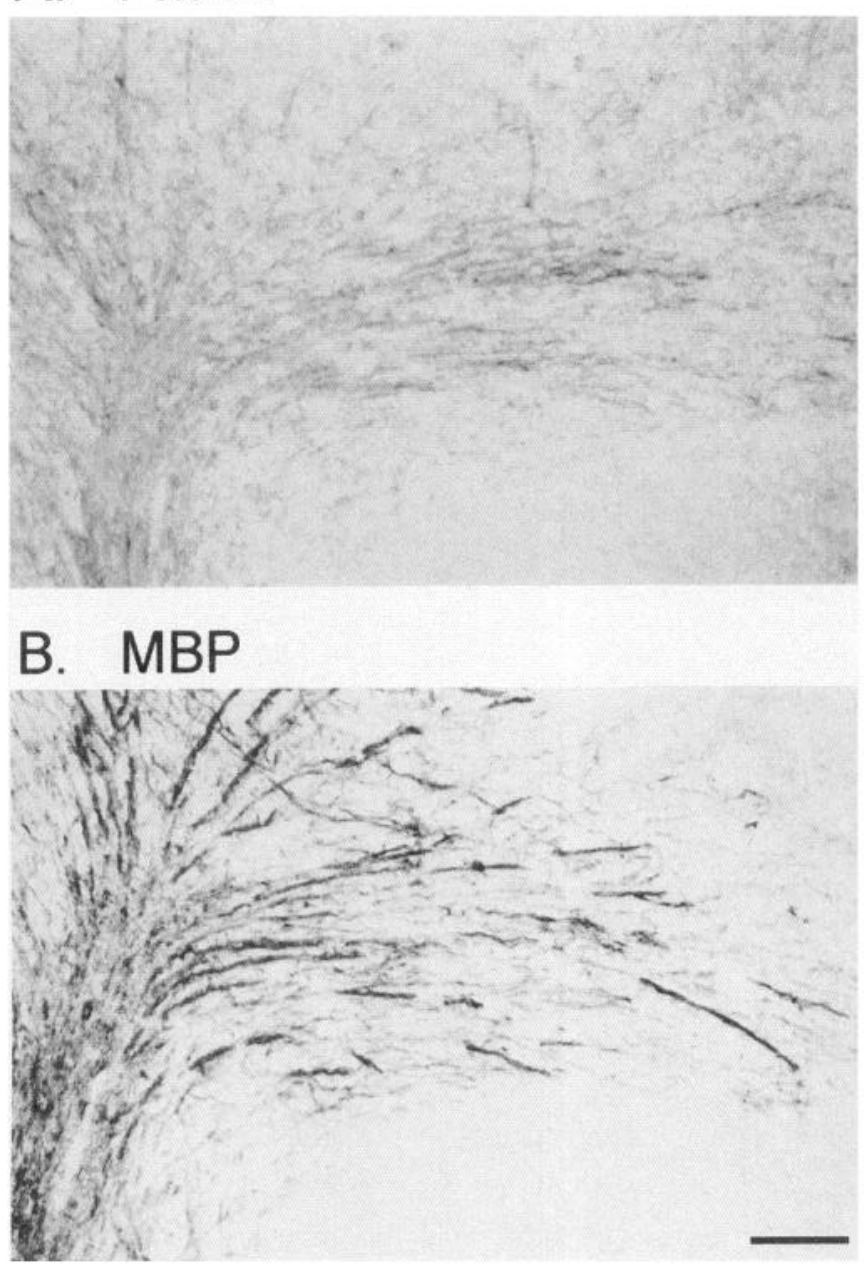

Figure 8. Localization of rMAL protein in the cerebellum. Immunoperoxidase detection of rMAL protein was performed with anti-rMAL peptide antiserum on sagittal sections of adult cerebellum $(A$, brightfield micrograph), rMAL immunoreactivity was confined to the white matter and to the myelinated fibers in the granule cell layer. In $B$, the myelin pattern is shown by immunoperoxidase detection of MBP on an adjacent cerebellar section. Scale bar: $A$ and $B, 380 \mu \mathrm{m}$.

\section{Structural relationship of rMAL to other four-hydrophobic domain proteins}

Although there are no obvious amino acid sequence homologies between $\mathrm{rMAL}$ and other proteins, the predicted protein showed interesting structural features. The putative rMAL protein belongs to the superfamily of four-hydrophobic domain proteins. This family includes the myelin proteins PLP/DM 20 and DM $\alpha$, $\mathrm{DM} \beta$ and $\mathrm{DM} \gamma$ (for review, see Kitagawa et al., 1993); the PLPrelated protein M6 (Yan et al., 1993); PMP-22 (Suter et al., 1992); the gap junction proteins of the connexin superfamily (Bennett et al., 1991); the ion channels nAChR, GluR, GABA-, NMDA-, and glycine receptor (for review, see Unwin, 1989); and others like the retinal photoreceptor protein peripherin-rds (Travis et al., 1991) and rom-1 (Bascom et al., 1992) and the lymphocyte antigen CD9 (Boucheix et al., 1991). It is not known yet whether all four hydrophobic domains of the MAL protein span the bilayer with the $\mathrm{C}$ - and $\mathrm{N}$-terminus on the cytoplasmic side of the membrane. Recent investigations of the transmembrane topology of the glutamate receptor GluR1 suggest that the four hydrophobic regions of this protein can, in fact, have different orientations; of four transmembrane domains of GluR 1 only three span the bilayer (Hollmann et al., 1994).

While PLP is predominantly localized in compact CNS myelin, PMP-22 expression is restricted to compact PNS myelin. Mutations of PLP cause massive myelin disorders in the CNS like in the jimpy and rumpshaker mouse, the myelin deficient rat and in Pelizaeus-Merzbacher disease in humans (Schneider et al., 1992). Mutations in the PMP-22 gene causes degenerative disorders in the PNS in the trembler mouse and Charcot-MarieTooth 1A disease in humans (Suter et el., 1993). Interestingly, most of the PLP and PMP-22 mutations that give rise to these serious neurological phenotypes are found in the transmembrane domains showing the important functional significance of these membrane-spanning regions. The main function of PLP seems to lay in the compaction of the extracellular part of the myelin lamellae, as this process is typically disturbed in these mutations. Since the putative rMAL protein is expressed in the myelinating cells of the CNS and PNS and shares important structural features with PLP and PMP-22, it may play an important role in central and peripheral myelin formation.

In contrast to PLP and PMP-22, the first and third putative transmembrane domain of the rMAL protein carries charged amino acids which lead to an amphipathic character of these segments. This structural feature is known from the gap junction proteins of the connexin family and from ion channel proteins (for review see Unwin, 1989) and CD9 (Boucheix et al., 1991). The polar amino acids of the third transmembrane domains of the connexins are thought to form the wall of the gap junction channel (Milks et al., 1988) which permits the passage of water soluble molecules. Connexins are four-transmembrane domain proteins which lack a cleavable signal peptide and are not glycosylated, similar to rMAL. So far, one member of the connexin superfamily, connexin 32 (Cx32), could be localized in oligodendrocytes and Schwann cells (Bergoffen et al., 1993). Mutations in the human $\mathrm{C} \times 32$ gene have been linked to CharcotMarie-Tooth disease type X (CMTX), a hereditary form of peripheral neuropathy. Although $\mathrm{Cx} 32$ is present also in liver, epithelial cells, some CNS neurons and oligodendrocytes (Bennett et al., 1991), the manifestations of CMTX appear to be limited to peripheral nerves. This suggests that a malfunction of $\mathrm{Cx} 32$ can be compensated for by other proteins except in peripheral myelin.

The correlation of the rMAL gene expression with the expression of several other myelin genes, the localization of rMAL protein in myelin sheaths and the similarity of rMAL protein to other myelin proteins with four hydrophobic domains point to a role of this highly hydrophobic membrane protein in myelin formation. Alternatively, rMAL could form or participate in the formation of channels or pores for the passage of small molecules. The possible relation of this new myelin protein to neuropathies of so far unknown origin, for example, CMT1C, should also be considered.

\section{References}

Alonso MA, Weissman SM (1987) cDNA cloning and sequence of MAL, a hydrophobic protein associated with human T-cell differentiation. Proc Natl Acad Sci USA 84:1997-2001.

Alonso MA, Barton DE, Franke U (1988) Assignment of the T-cell differentiation gene MAL to human chromosome 2, region cen-q13. Immunogenetics 27:91-95.

Bascom RA, Manara S, Collins L, Molday RS, Kalnins I, McInnes VI (1992) Cloning of the cDNA for a novel photoreceptor membrane 
protein (rom-1) identified a disk rim protein family implicated in human retinopathies. Neuron 8:1171-1184.

Bennett MVL, Barrion LC, Bargiello TA, Spray DC, Hertzberg E, Saez JC (1991) Gap junctions: new tools, new answers, new questions. Neuron 6:305-320.

Bergoffen J, Scherer SS, Wang S, Oronzi SM, Bone LJ, Paul DL, Chen K, Lensch MW Chance PF, Fischbeck KH (1993) Connexin mutations in X-linked Charcot-Marie-Tooth Disease. Science 262:20392042.

Boison D, Stoffel W (1989) Myelin-deficient rat: a point mutation in exon III (A to C, Thr75 to Pro) of the myelin proteolipid protein causes dysmyelination and oligodendrocyte death. EMBO J 8:32953302.

Bothwell A, Yancopoulos GD, Alt FW (1990) Methods for cloning and analysis of eukaryotic genes. Boston: Jones and Bartlett.

Boucheix C, Benoit P, Frachet P, Billard M, Worthington RE, Gagnon J, Uzan G (1991) Molecular cloning of the CD9 antigen: a new family of cell surface proteins. J Biol Chem 266:117-122.

Caroni P, Schwab ME (1988) Two membrane protein fractions from rat central myelin with inhibitory properties for neurite growth and fibroblast spreading. J Cell Biol 106:1281-1288.

Colman DR, Kreibich G, Frey AB, Sabatini DD (1982) Synthesis and incorporation of myelin peptides into CNS myelin. J Cell Biol 95: $598-608$.

Dermietzel R, Spray DC (1993) Gap junctions in the brain: where, what type, how many and why? Trends Neurosci 16:186-192.

Doyle JP, Colman DR (1993) Glial-neuron interaction and the regulation of myelin formation. Curr Opinion Cell Biol 5:779-785.

Filbin MT, Walsh FS, Trapp BD, Pizzey JA, Tennekoon GI (1990) Role of myelin $\mathrm{P}_{0}$ protein as a homophilic adhesion molecule. Nature 344: $871-872$.

Gimlich RL, Kumar NM, Gilula NB (1988) Sequence and developmental expression of mRNA coding for a gap junction protein in Xenopus. J Cell Biol 107:1065-1073.

Hayasaka K, Himoro M, Sawaishi Y, Nanao K, Takahashi T, Takada G, Nicholson A, Ouvrier R, Tachi N (1993) De novo mutation of the myelin $\mathrm{P}_{0}$ gene in Dejerine-Sottas disease (heredity motor and sensory neuropathy type III). Nature Genetics 5:266-268.

Hollmann M, Maron C, Heinemann S (1994) N-Glycosylation site tagging suggests a three transmembrane domain topology for the glutamate receptor GluR1. Neuron 13:1331-1343.

Hudson LD (1990) Molecular biology of myelin proteins in the central and peripheral nervous system. The Neurosci $2: 483-496$.

Hudson LD, Berndt JA, Puckett C, Kozak CA, Lazzarini RA (1987) Aberrant splicing of proteolipid protein mRNA in the dysmyelinating jimpy mutant mouse. Proc Natl Acad Sci USA 84:1454-1458.

Hudson LD, Puckett C, Berndt J, Chan J, Gencic S (1989) Mutation of the proteolipid protein gene PLP in a human X chromosome-linked myelin disorder. Proc Natl Acad Sci USA 86:8128-8131.

Jacobson S (1963) Sequence of myelination in the brain of the albino rat. A. Cerebral cortex, thalamus and related structures. J Comp Neurol 121:5-21.

Jordan C, Friedrich V Jr, Dubois Dalq M (1989) In situ hybridization analysis of myelin gene transcripts in developing mouse spinal cord J Neurosci 9:248-257.

Kitagawa K, Sinoway MP, Yang C, Gould RM, Colman DR (1993) A proteolipid protein gene family: expression in sharks and rays and possible evolution from an ancestral gene encoding a pore-forming polypeptide. Neuron 11:433-448.

Kyte J, Doolittle RF (1982) A method for displaying the hydropathic character of a protein. J Mol Biol 157:105-132.

Mahmoudi M, Lin VR (1989) Comparison of two different hybridization systems in Northern transfer analysis. Biotechniques 7:331-333.

Mikol DD, Gulcher JR, Steffansson (1990) The oligodendrocyte-myelin glycoprotein belongs to a distinct family of proteins and contains the HNK-1 carbohydrate. J Cell Biol 110:471-479.

Mikoshiba M, Okano H, Tamura T, Ikenaka K (1991) Structure and function of myelin protein genes. Annu Rev Neurosci 14:201-217.

Milks LC, Kumar NM, Houghten R, Unwin N, Gilula NB (1988) To- pology of the 32-kd gap junction protein determined by site-directed antibody localizations. EMBO J 7:2967-2975.

Milner RJ, Lai C, Nave K-A, Lenoir D, Ogata J, Sutcliffe JG (1985) Nucleotide sequences of two mRNAs for rat brain myelin proteolipid protein. Cell 42:931-939.

Mirsky R, Jessen KR (1990) Schwann cell development and the regulation of myelination. Semin Neurosci 2:423-435.

Moscarello MA (1989) Myelin basic protein, a dynamically changing structure. In: Dynamic interactions in myelin (Hashim G, Moscarello MA, eds). New York: Liss

Nave K-A, Milner RJ (1989) Proteolipid proteins: structure and genetic expression in normal and myelin-deficient mutant mice. Crit Rev Neurobiol 5:65-91.

Popot J-L, Dinh DP, Dautigny A (1991) Major myelin proteolipid: the 4- $\alpha$-helix topology. J Membr Biol 120:233-246.

Posnett DN, McGrath H, Tam JP (1988) A novel method for producing anti-peptide antibodies: production of site-specific antibodies to the $\mathbf{T}$ cell antigen receptor $\boldsymbol{\beta}$-chain. J Biol Chem 263:1719-1725.

Rozeik C, Von Keyserlingk D (1987) The sequence of myelination in the brainstem of the rat monitored by myelin basic protein immunohistochemistry. Dev Brain Res 35:183-190.

Salzer JL, Perdraza L, Brown M, Struyk A, Afar D, Bell J (1990) Structure and function of the myelin-associated glycoproteins. Ann NY Acad Sci 605:302-312.

Schaeren-Wiemers N, Gerfin-Moser A (1993) Single protocol to detect transcripts of various types and expression levels in neural tissue and cultured cells; in situ hybridization using Digoxigenin-labeled cRNA probes. Histochemistry 100:431-440.

Schaeren-Wiemers N, Schaefer C, Valenzuela DM, Yancopoulos GD, Schwab ME (1995) Identification of new oligodendrocyte- and myelin-specific genes by a differential screening approach. J Neurochem 65: in press.

Schneider A, Montague P, Griffiths I, Fanarraga M, Kennedy P, Brophy P, Nave K-A (1992) Uncoupling of hypomyelination and glial cell death by a mutation in the proteolipid protein gene. Nature 358:758761.

Schwab ME, Schnell L (1989) Region-specific appearance of myelin constituents in the developing rat spinal cord. J Neurocytol 18:161169.

Snipes GJ, Suter U, Welcher AA, Shooter EM (1992) Characterization of a novel peripheral nervous system myelin protein (PMP-22/SR13). J Cell Biol 117:225-238.

Sommer I, Schachner M (1981) Monoclonal antibody (O1 to O4) to oligodendrocytc ccll surfaces: an immunocytological study in the central nervous system. Dev Biol 83:311-327.

Suter U, Welcher AA, Özcelik T, Snipes GJ, Kosaras B, Francke U, Billings-Gagliardi S, Sidman RL, Shooter EM (1992) Trembler mouse carries a point mutation in a myelin gene. Nature 356:241-244.

Suter U, Welcher AA, Snipes GJ (1993) Progress in the molecular understanding of hereditary peripheral neuropathies reveals new insights into the biology of the peripheral nervous system. Trends Neurosci 16:50-56.

Tam IP (1988) Synthetic peptide vaccine design: synthesis and properties of a high-density multiple antigenic peptide system. Proc Natl Acad Sci USA 85:5409-5413.

Travis GH, Sutcliff JG, Bok D (1991) The retinal degeneration slow (rds) gene product is a photoreceptor disc membrane-associated glycoprotein. Ncuron 6:61-70.

Unwin N (1989) The structure of ion channels in membranes of excitable cells. Neuron 3:665-676.

Welcher AA, Suter U, De Leon M, Snipes GJ, Shooter EM (1991) A myelin protein is encoded by the homologue of a growth arrest-specific gene. Proc Natl Acad Sci USA 88:7195-7199.

Yan Y, Lagenaur C, Narayanan V (1993) Molecular cloning of M6: identification of a PLP/DM20 gene family. Neuron 11:423-431.

Zeller NK, Hunkeler MJ, Campagnoni A, Sprague J, Lazzarini RA (1984) Characterization of mouse myelin basic protein messenger RNAs with a myelin basic protein cDNA clone. Proc Natl Acad Sci USA $81: 18-22$. 